\title{
ELISA and modified toxin-binding inhibition test for quality control of the clostridial vaccine processes
}

\author{
[ELISA direto e ToBI-test modificado para o controle de qualidade de \\ processos de vacinas clostridiais] \\ E.M. Sobrinho ${ }^{1}$, A.C. Almeida ${ }^{2}$, I.V. Brandi ${ }^{2}$, F. Colen $^{2}$, F.C.F. Lobato ${ }^{3}$,

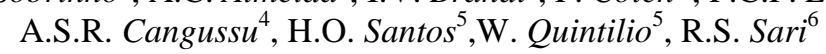

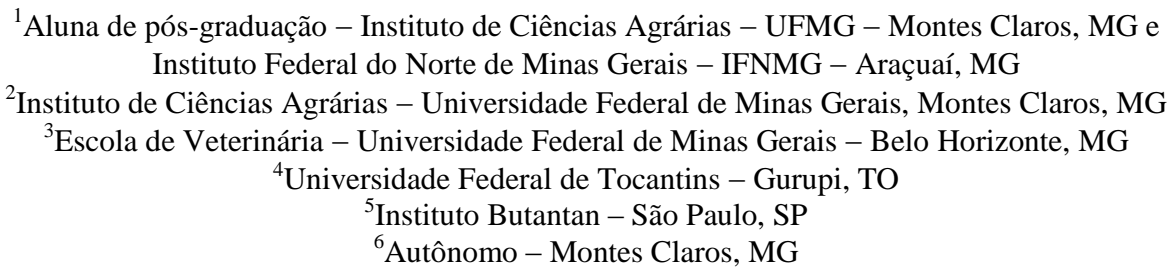

\begin{abstract}
This study aimed to assess and standardize the ELISA and modified ToBI test in vitro methods in order to verify the potency of epsilon toxicoid in comparison with the in vivo TCP method. The following epsilon toxoids were used: NIBSC standard from batches 375/07, 532/08, 551/08, 373/07 and 378/07. These were evaluated using a TCP test, ELISA and ToBI tests. The results indicate that the correlation ratio between the dilutions of standard NIBSC toxicoid and absorbance values of $89.44 \%$ obtained with the ELISA method support the use of the curve to evaluate epsilon toxoids. However, it was observed that the absorbance values were similar for all toxoids, thus presenting no significant difference between higher and lower concentration toxoids. For the ToBI test, the correlation ratio of 96.76, obtained in the curve pattern, demonstrates the effectiveness of the curve to be used in the epsilon toxoid evaluation. The correlation ratio between the titration degrees of toxoids obtained through TCP and ToBI tests was higher than 90\%. It is concluded that the type of ELISA test used does present discriminative power for toxoids with different concentrations, which does not support the use of this technique for such a purpose. The ToBI test can be used as a screening method for it is sensitive and effective to detect epsilon toxicoid produced by $C$. perfringens type D.
\end{abstract}

Keywords: epsilon toxicoid, clostridiosis, in vitro alternative method

\section{RESUMO}

Teve-se por objetivo avaliar e padronizar as metodologias in vitro, ELISA e ToBI-test modificado, para a análise de toxoide épsilon, em comparação com a metodologia in vivo TCP. Foram utilizados os seguintes toxoides épsilon: padrão NIBSC e os lotes 375/07, 532/08, 551/08, 373/07 e 378/07, os quais foram avaliados por métodos in vivo, TCP, $e$ in vitro, ELISA e ToBI-test. A análise do título de toxoide épsilon por meio dos métodos in vitro foi realizada a partir de uma curva-padrão, estabelecida previamente. Os principais resultados mostram que os valores de absorbância foram semelhantes para todos os toxoides, não apresentando diferença significativa entre os toxoides mais concentrados e menos concentrados. No ToBI-test, o coeficiente de correlação de 96,76\%, obtido na curva-padrão, demonstra a eficiência da curva para avaliação do toxoide épsilon. O coeficiente de correlação entre os títulos de toxoide obtidos pelo TCP e ToBItest foi superior a 90\%. Conclui-se que o tipo de ELISA utilizado não apresenta poder discriminativo para toxoides com diferentes concentrações, inviabilizando a técnica para esse fim. O ToBI-test pode ser utilizado como um método de triagem sensível e eficaz para a detecção de toxoide épsilon de C. perfringens tipo D.

Palavras-chave: toxoide épsilon, clostridioses, método alternativo in vitro

Recebido em 6 de março de 2012

Aceito em 12 de dezembro de 2013

E-mail: elianemsobrinho@hotmail.com.br 


\section{INTRODUCTION}

Bacterial veterinary vaccines occupy an expressive market in the bovine and ovine business. The main products for this segment are the vaccines against clostridiosis, which represent $90 \%$ of the bacterial vaccine market. Bacteria of the genus Clostridium are etiological agents which cause several diseases in animals, ailments known as clostridiosis (Hatheway, 1990). Given the importance of these vaccines for the market, and, above all, due to international business exchanges, countries are asked to make harsher decisions regarding the quality control of farm equipment and biological products. The interest from the national and international market for vaccines against enterotoxemy justifies the need for the development of tests which detect levels or concentrations of toxoids to be used in vaccines.

In the control process of vaccine manufacturing the methods of toxicoid titration employed are generally carried out in mice, the most common being the $\mathrm{DL}_{50}$, Lethal dose $50 \%$ (Reed and Muench, 1938). There are other methods for toxin titration, such as MMD (Minimum Mortal Dose) and L+ (United States, 2006). For the titration of toxoids, methods such as TCP (Total Combining Power) are used, which involve the partial neutralization of a fixed dose of antitoxin with a series of variant doses of the toxicoid being tested (Walker et al., 1979). Besides being very specific, the in vivo tests have limitations in terms of sensibility.

The toxin-antitoxin reaction is used to determine antibody levels in sera from immunized animals, and is used by official control agencies or vaccine manufacturers to assess the efficacy of clostridial vaccines and to certify their quality (Sobrinho et al., 2010). New methods for quantification of antigens are desired. This kit allows for the detection and quantification of antigens that are necessary for the vaccine formulation (Sobrinho et al., 2011). These tests, known as the toxin binding inhibition (ToBI) test and the Enzyme Linked Immuno Sorbent Assay (ELISA) aimed to evaluate the quality of veterinary vaccines in order to replace or minimize the procedures that use laboratory animals (Sobrinho et al., 2010). Other similar alternatives have been developed with the same purpose (Sobrinho et al., 2009). The ELISA, in its diverse variations, has been utilized and evaluated by many researchers. However, there are few reports in literature showing an evaluation of the $T o B i$ test in the antigen components of clostridial vaccines.

This study was triggered by the growing interest in the development of immunological techniques in vitro for the control of clostridial antigens, since the efficiency of the in vitro method in the detection of the toxin and toxoids, the advantages in terms of sensitivity and result quickness, as well as its relevancy in the routine of veterinary pharmaceutical industries, are well known (El Idrissi and Ward, 1992a, 1992b).

In this context, this study had the purpose of evaluating and standardizing the in vitro methodologies for direct modified ELISA and modified ToBi tests in the analysis of the epsilon toxicoid, in comparison to the TCP in vivo test. The results will enable an analysis of the viability of the ToBi test as a new technique in the quality control of the toxicoid.

\section{MATERIAL AND METHODS}

This study utilized the $2^{\text {nd }}$ international standard for the epsilon antitoxin of Clostridium perfringens type D (2CpEpsilonAt), prepared and characterized by Veterinary Laboratories Agency (Weybridge, Surrey, United Kingdom), whose custody and distribution rights belong to the National Institute for Biological Standards and Control - NIBCS (Potters Bar, United Kingdom). The epsilon toxin of Clostridium perfringens type $\mathrm{D}$, produced in environment, as suggested by Brandi (2000), at $37^{\circ} \mathrm{C}, 200 \mathrm{rpm}$, for 15 hours, was standardized with the L+/10 test (United States..., 2006). The toxins were clarified by tangential filtration and, afterwards, submitted to an inactivation process with formaldehyde at $37 \%$. After this detoxification process the suspensions were denominated toxoids. Both toxins and toxoids were produced and given by the Laboratory of Vaccine Technology.

The polystyrene and immunoassay plates, as well as the washing solution $(\mathrm{NaCl} 0.9 \% \mathrm{p} / \mathrm{v}$ solution containing $0.05 \%$ of Tween-20), added with rabbit antiserum SIGMA $^{\circledR}$, ortophenylene diamine enzymatic substrate $(0.4 \mathrm{mg} / \mathrm{mL})$ with volume 30 hydrogen peroxide $(0.2 \mu \mathrm{L} / \mathrm{mL})$ 
prepared in a citrate buffer solution $0.15 \mathrm{M}, \mathrm{pH}$ 5.0 and solution $2 \mathrm{M} \mathrm{H}_{2} \mathrm{SO}_{4}$ was supplied by the Laboratory of Vaccine Technology of Vallee S.A. The substrate was prepared by dissolving $10 \mathrm{mg}$ of OPD in $25 \mathrm{~mL}$ of citrate buffer, in a concentration of $0.15 \mathrm{M}$ and $\mathrm{pH} 5$, added with $12.5 \mu \mathrm{L}$ of hydrogen peroxide diluted $1: 1150$ off the pure sample. It was incubated at $37^{\circ} \mathrm{C}$ for 60 minutes and then $20 \mu \mathrm{L}$ of sulfuric acid was added, diluted 1:20 off the pure one to finish the reaction. This substrate was prepared at the moment for use.

In the evaluation of the epsilon toxicoid through the in vivo technique, the TCP method was used (Brandi, 2007). Six different toxoids were employed: NIBSC standard and the batch 375/07, 532/08, 551/08, 373/07 and 378/07.

The standard NIBSC epsilon toxicoid, after being submitted to titration in mice (Brandi, 2007), was employed in eight different dilutions, identified as D1, D2, D3, D4, D5, D6, D7 and D8.

The stage of TCP was obtained by carrying out dilutions of the toxicoid in series, utilizing factor 4. Next, $0.25 \mathrm{~mL}$ of each of the dilutions was mixed with $0.25 \mathrm{~mL}$ of standard epsilon toxin containing $2 \mathrm{UI} / \mathrm{mL}$ and maintained at room temperature for 1 hour. After this period, 0.25 of standard toxin containing $10 \mathrm{~L}+/ 10 / \mathrm{mL}$ was added to the tube containing toxicoid and antitoxin, obtaining a solution of $0.75 \mathrm{~mL}$. To this volume $0.25 \mathrm{~mL}$ of saline was added to obtain a final volume of $1 \mathrm{~mL}$ and incubated at room temperature for 30 minutes; $0.2 \mathrm{~mL}$ was endovenously inoculated in two mice, by dilution.

The animals were observed for a period of seven days, the deaths being recorded daily in a specific protocol. The TCP result was calculated based on the toxicoid dilution level in which all the mice died.

To obtain more precise results, a second phase of the test was conducted to determine the interval between the dilution in which animals died and dilution in which all animals lived. It was determined by preparing dilutions every $30 \%$, starting from the dilution of the first stage in which all mice died. The $30 \%$ intervals were the smallest intervals obtained so as not to confuse the limits of death and life of the animals, due to proximity of the dilutions.

The modified direct ELISA technique utilized in this study for quantification of epsilon toxicoid followed the recommendations suggested by Uzal et al. (1997), with the following adaptations: the plates were sensitized by putting in each plate orifice $100 \mu \mathrm{L}$ of rabbit anti-epsilon antibody serum in a concentration of $5 \mathrm{UI} / \mathrm{mL}$ diluted in $1: 2$ with carbonate and bicarbonate sensitization buffer $(0.05 \mathrm{M}$ and $\mathrm{pH}$ 9.6). The dilution employed was previously established. After 12 hours of incubation at $4^{\circ} \mathrm{C}$, the plate was blocked with $200 \mu \mathrm{L}$ of $3 \%$ albumin solution and incubated at $37 \mu \mathrm{L}$ for 60 minutes. After a sequence of 6 washings, $100 \mu \mathrm{L}$ of test toxicoid was added in each plate orifice and incubated again at $37^{\circ} \mathrm{C}$, for 60 minutes. Next, $100 \mu \mathrm{L}$ of rabbit anti-serum conjugate was added, diluted in dilution buffer and incubated at $37^{\circ} \mathrm{C}$, for $60 \mathrm{~min}$. Finally, $100 \mu \mathrm{L}$ of enzymatic substrate (OPD) was added and placed in a dark chamber for 10 minutes.

The methodology adopted to conduct the modified ToBI test for evaluation of epsilon toxicoid followed the recommendations suggested by Fayez et al. (2005), with the following adaptations: the dilution plate was blocked by adding $250 \mu \mathrm{L}$ of $3 \%$ albumin solution. Next, in each plate orifice, $100 \mu \mathrm{L}$ of epsilon toxicoid was added, diluted according to needs, with dilution buffer. On the same plate, $100 \mu \mathrm{L}$ of NIBSC standard antitoxin was added containing $1 \mathrm{UI} / \mathrm{mL}$, in each of the orifices. The plate was agitated and incubated at $37^{\circ} \mathrm{C}$, in humid atmosphere, for 60 minutes.

In the sensitization stage, the plate was sensitized by putting $100 \mu \mathrm{L}$ of NIBSC standard epsilon antitoxin diluted in bicarbonate and carbonate sensitization buffer $(0.05 \mathrm{M}$ and $\mathrm{pH} 9.6)$ to contain $1 \mathrm{UI} / \mathrm{mL}$. After 12 hours of incubation at $4^{\circ} \mathrm{C}$, the plate was washed and then blocked with $200 \mu \mathrm{L}$ of $3 \%$ albumin solution. The plate was incubated at $37^{\circ} \mathrm{C}$ for 60 minutes. After a sequence of 6 washings, in each plate orifice $100 \mu \mathrm{L}$ of the toxoid mixture and NIBSC standard antitoxin was added and incubated afterwards at $37^{\circ} \mathrm{C}$, for 60 minutes. After washing it, $100 \mu \mathrm{L}$ of rabbit antibody anti-epsilon serum was added, followed by the addition of $100 \mu \mathrm{L}$ of rabbit anti-serum conjugate diluted in 
buffer and incubated again at $37^{\circ} \mathrm{C}$ for 60 minutes. After this period, $100 \mu \mathrm{L}$ of enzymatic substrate (OPD) was added and maintained in a dark chamber for 10 minutes.

\section{RESULTS}

The standard NIBSC epsilon toxoid used in this study presented a result equal to $2560 \mathrm{TCP} / \mathrm{mL}$ in the titration with mice. When diluted in series from D1 to D6 using factor 2, varied results were obtained in accordance with the concentration of each dilution, when quantified in vivo by means of TCP methodology (Table 1). The results obtained through TCP are described as reciprocal to the dilution where the death of the inoculated animals occurred.

The results of the TCP technique linearity are showed in Table 1.

Table 1. NIBSC Standard epsilon toxoid titles in serial dilutions (1:4 to $1: 65536)$ obtained through the in vivo TCP methodology

\begin{tabular}{ccc}
\hline $\begin{array}{c}\text { Standard } \\
\text { toxicoid }\end{array}$ & TCP / mL & Ln TCP / mL \\
\hline D1 & 640 & 6.461 \\
D2 & 320 & 5.768 \\
D3 & 160 & 5.075 \\
D4 & 80 & 4.382 \\
D5 & 40 & 3.689 \\
D6 & 20 & 2.996 \\
D7 & 10 & 2.303 \\
D8 & $<1$ & 0 \\
\hline
\end{tabular}

Different batches of epsilon toxoid produced by the Laboratory of Vaccine Technology were tested in order to correlate the values obtained through this technique and the results obtained through in vitro, ELISA and ToBi tests. The purpose of this analysis was to examine if the in vitro, ELISA and ToBi test techniques were sensitive enough to differentiate toxoids of different qualities.

The titration results of different batches of epsilon toxoid obtained through in vivo and in vitro methodologies are presented in Table 2.

It was observed that the rabbit anti-epsilon immunoglobulin diluted 1:4 was efficient to sensitize the plate and generate absorbance close to 1 to $492 \mathrm{~nm}$ when the NIBSC standard toxicoid was utilized. The conjugated antibody was diluted at 1:20.000 as recommended by the manufacturer.

After establishing the concentration of rabbit immunoglobulin, capable of sensitizing the plate, the standard toxoid was diluted in a dilution series by utilizing factor-two dilution to correlate with the values of absorbance and elaborate a standard curve. The elaboration of the standard curve was utilized for the quantification of antigens, in $\mathrm{TCP} / \mathrm{mL}$, through the direct modified ELISA technique.

The coefficient of correlation between the dilutions of standard NIBSC toxicoid and the values of absorbance reached $89.44 \%$, thus showing a satisfactory correlation between the parameters and making the utilization of the curve viable for the evaluation of epsilon toxoid, for high values of correlation in the standard curve originate reliable results.

On evaluating the different batches of toxoids through in vitro, modified direct ELISA, it was verified that the values of absorbance were similar for all toxoids, not presenting significant difference among the most (375/07) and less concentrated toxoids $(378 / 07)$.

In the evaluation of the modified ToBi test for the evaluation of the epsilon toxoid, the NIBSC standard epsilon antitoxin with $8 \mathrm{UI} / \mathrm{mL}$, diluted $1: 4$, seemed to be sufficient to sensitize the plates, and the sheep immunoglobulin rabbit anti-immunoglobulin, conjugated to peroxidase, was used in a 1:20.000 dilution as recommended by the manufacturer.

The rabbit immunoglobulin with $5 \mathrm{UI} / \mathrm{mL}$ was assayed pure and in 1:2, 1:4, 1:8, 1:16 and 1:32 dilutions. The dilution chosen was 1:4 for the rabbit immunoglobulin. To analyze the toxoids, a standard curve was created and utilized together with the analysis of each toxoid. The elaboration of the curve was done by using the standard NIBSC toxoid, diluted in series from the dilutions $1: 640$ to $1: 10$, utilizing dilution factor 2. A negative control was also utilized in the elaboration of the curve. Figure 1 shows the values of absorbance obtained in each of the toxicoid concentrations analyzed through the ToBi test. 
Table 2. Titles of epsilon toxoid (TCP/mL), by the ToBI test method, in plates 1,2 and 3 , with the respective values of absorbance and standard deviation of each measured point

\begin{tabular}{|c|c|c|c|c|c|c|c|}
\hline Toxicoid & $\mathrm{A}_{492} \mathrm{~nm}$ & $\begin{array}{c}\mathrm{Ln} \\
\mathrm{TCP} / \mathrm{mL}\end{array}$ & $\mathrm{TCP} / \mathrm{mL}$ & $\begin{array}{c}\mathrm{Ln} \\
\mathrm{TCP} / \mathrm{mL}\end{array}$ & $\mathrm{TCP} / \mathrm{mL}$ & $\frac{\text { In vitro }}{\text { in vivo }}$ & $\mathrm{SD}(\delta)$ \\
\hline & \multicolumn{3}{|c|}{ In vitro - Plate 1} & \multicolumn{2}{|c|}{ In vivo } & & \\
\hline Pattern & 1,982 & 14,041 & 1.252 .936 & 7,848 & 2560,00 & 489,00 & 0,046 \\
\hline $375 / 07$ & 1,985 & 14,058 & 1.274 .418 & 7,848 & 2560,00 & 497,80 & 0,016 \\
\hline $551 / 08$ & 1,415 & 10,216 & $27.337,00$ & 7,313 & 1500,00 & 18,220 & 0,030 \\
\hline $532 / 08$ & 1,113 & 8,178 & $3.562,00$ & 7,031 & 1131,00 & 3,150 & 0,019 \\
\hline $373 / 07$ & 0,894 & 6,705 & 816,00 & 6,215 & 500,00 & 1,630 & 0,017 \\
\hline $378 / 07$ & 0,624 & 4,881 & 132,00 & 5,075 & 160,00 & 0,825 & 0,018 \\
\hline \multirow[t]{2}{*}{ Average } & 1,336 & 9,680 & 426533,50 & 5,580 & 1401,833 & 168,438 & 0,024 \\
\hline & \multicolumn{3}{|c|}{ In vitro - Plate 2} & \multicolumn{2}{|c|}{ In vivo } & & \\
\hline Pattern & 1,976 & 13,998 & 1.200 .201 & 7,848 & 2560,00 & 489,00 & 0,017 \\
\hline $375 / 07$ & 1,975 & 13,990 & 1.190 .638 & 7,848 & 2560,00 & 465,09 & 0,016 \\
\hline $551 / 08$ & 1,425 & 10,280 & $29.144,00$ & 7,313 & 1500,00 & 19,430 & 0,010 \\
\hline $532 / 08$ & 1,122 & 8,238 & $3.7820,00$ & 7,031 & 1131,00 & 3,340 & 0,006 \\
\hline $373 / 07$ & 0,884 & 6,637 & 763,00 & 6,215 & 500,00 & 1,530 & 0,017 \\
\hline $378 / 07$ & 0,631 & 4,927 & 138,00 & 5,075 & 160,00 & 0,862 & 0,127 \\
\hline \multirow[t]{2}{*}{ Average } & 1,336 & 9,678 & 404111,00 & 5,580 & 1401,833 & 168,438 & 0,032 \\
\hline & \multicolumn{3}{|c|}{ In vitro - Plate 3} & \multicolumn{2}{|c|}{ In vivo } & & \\
\hline Pattern & 1,985 & 14,058 & 1.274 .418 & 7,848 & 2560,00 & 489,00 & 0,037 \\
\hline $375 / 07$ & 1,983 & 14,046 & 1.259 .216 & 7,848 & 2560,00 & 491,88 & 0,024 \\
\hline $551 / 08$ & 1,420 & 10,246 & 28.170 & 7,313 & 1500,00 & 18,780 & 0,012 \\
\hline $532 / 08$ & 1,118 & 8,211 & $3.681,00$ & 7,031 & 1131,00 & 3,250 & 0,006 \\
\hline $373 / 07$ & 0,892 & 6,689 & 803,00 & 6,215 & 500,00 & 1,610 & 0,013 \\
\hline $378 / 07$ & 0,622 & 4,869 & 130,00 & 5,075 & 160,00 & 0,810 & 0,014 \\
\hline Average & 1,337 & 9,687 & 427736,33 & 5,580 & 1401,833 & 168,438 & 0,018 \\
\hline
\end{tabular}

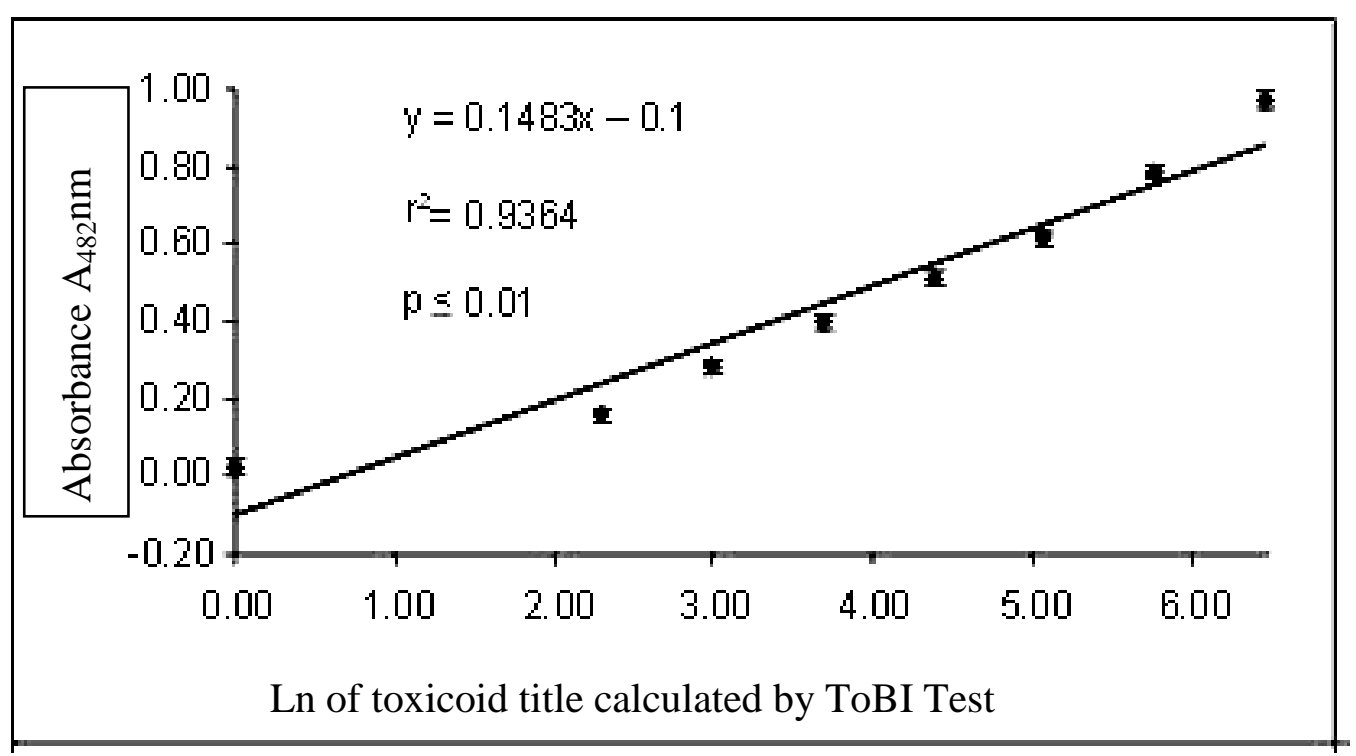

Figure 1. Standard curve showing the correlation between the ToBI test absorbance values $\left(\mathrm{A}_{492 \mathrm{~nm}}\right)$ and the neperian logarithm $(\mathrm{Ln})$ of the epsilon toxoid values $(\mathrm{TCP} / \mathrm{mL})$.

After establishing the standard curve, six different epsilon toxoids were evaluated through the modified ToBi test. The results are presented in Table 2. 
The intraplate coefficient of variation varied from 0.502 to $8.447 \%$, while the interplate was from 4.892 to $14.032 \%$.
Figure 2 represents the curves of existing correlations between the ToBi test, modified for the analysis of toxoids and titration in vivo by utilizing mice.
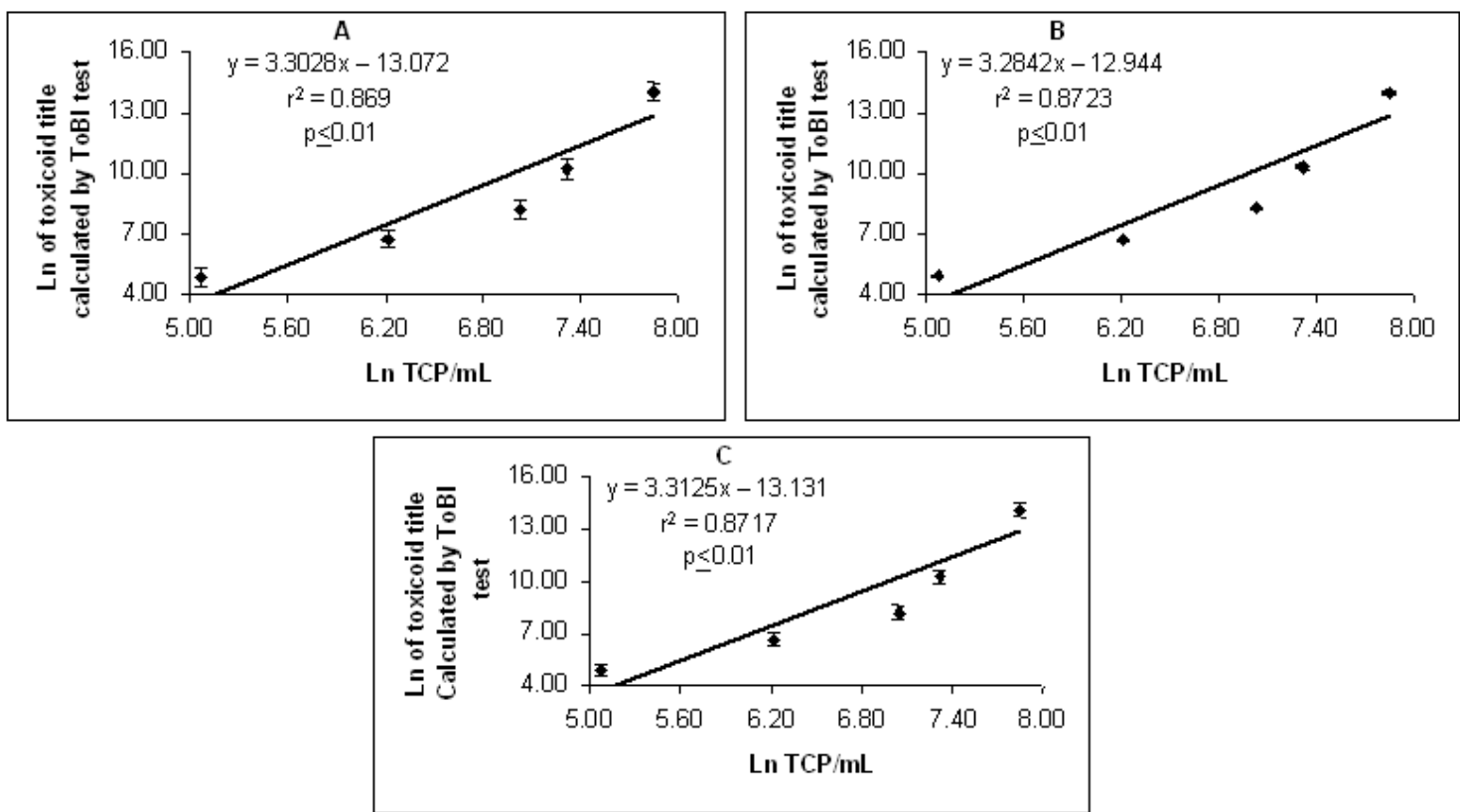

Figure 2. Relationship between the epsilon toxoid titles ( $\mathrm{Ln} \mathrm{TCP} / \mathrm{mL})$ obtained through the TCP in vivo and ToBI test methods, in plates 1, 2 and 3, represented in A, B and C, respectively.

\section{DISCUSSION}

The results in Tab. 1 showed that the TCP technique presents linearity for the dilutions in the series of $1: 2$ to $1: 64$, for the results were proportional to the concentration of the substance under analysis in the sample. These results corroborate the results obtained by Brandi (2007), who, by using a linear Regression, obtained a coefficient of correlation equal to 0.9999, which enabled him to affirm that to measure epsilon toxoid, the TCP technique presents linearity up to 1:256 dilution factor. The importance of evaluating the parameter of linearity for a titration technique lies in the fact that on carrying out sample dilutions one needs to be sure that the diluted sample has the expected substance concentration, according to the dilution made.

Results obtained by Brandi (2007) showed that it is possible to quantify samples with elevated concentrations of toxoid through a dilution series of the sample. This author concluded further that the toxicoid can be quantified in distinct days, up to six days, with no loss of titration in this period. The technique is seen as robust, for it proved that the sample may be titrated both at 34 , 37 and $40^{\circ} \mathrm{C}$, in $\mathrm{pH}$ values of 6.7 to 7.7 and in reaction times of 40, 60 and 80 minutes of antitoxin with toxoid, without variation in the result, as well as reaction times 10, 30 and 50min of the toxin reaction with toxoid and antitoxin.

It was observed that the rabbit anti-epsilon immunoglobulin diluted at 1:4 was efficient to sensitize the plate and generate absorbance close to 1 to $492 \mathrm{~nm}$, when the NIBSC standard toxicoid was utilized. In the study conducted by El Idrissi and Ward (1992a, 1992b), the dilution of choice was 1:8000, which could indicate a more concentrated antitoxin. However, it should be kept in mind that the types of ELISA used differed between the studies.

The values of absorbance were similar for all toxoids. These results indicate that the modified direct ELISA test, evaluated in this study, was not capable of discriminating different quantities of toxoids in the sample, thus making unviable 
for this purpose. The toxoids utilized presented values of absorbance close to the others, namely, $0.386,0.357,0.401,0.399$ and 0.421 for all the toxoids of the batches 375/07, 532/08, 551/08, $373 / 07$ and 378/07, respectively. These results differed from the result obtained when the NIBSC standard toxicoid was utilized, which presented an absorbance of 0.805 . This fact suggests that the samples submitted to the purification process, as in the case of the NIBSC standard toxoid, yield different results from the toxoids that did not undergo a more rigorous purification process, besides diafiltration and ultrafiltration. This way, the degree of purity of the toxoid is preconized as an important factor in the success of the modified direct ELISA technique.

Several authors report the efficiency of the ELISA technique in the quantification of vaccine antigens. However, as this study demonstrated, it depends on the type of ELISA being utilized. For instance, the sandwich ELISA (El Idrissi and Ward, 1992a, 1992b), was capable of detecting, in a linear form, concentrations between 7.8 and $125 \mathrm{ng} / \mathrm{mL}$ and the minimum detectable $2 \mathrm{ng} / \mathrm{mL}$. Nagahama et al. (1991) reported that the sensitivity of ELISA with specific antibodies for the detection of beta, epsilon and iota toxins of C. perfringens may reach up to $1.0 \mathrm{mg} / \mathrm{mL}$ for the purified iota and beta toxins and $0.1 \mathrm{ng} / \mathrm{mL}$ of purified epsilon toxin. Uzal et al. (2003) reported the detection of $0.075 \mathrm{DL}_{50} / \mathrm{mL}$ of epsilon toxin in the intestinal content. By comparing the sandwich ELISA and the serumneutralization for the detection of beta and epsilon toxin in intestine content, a study found a sensibility and specificity of $90.5 \%$ and $89.2 \%$ for the beta toxin and 97.4 and 95.6 for the epsilon toxin (El Idrissi and Ward, 1992a, 1992b). On the other hand, this study showed no promising results when utilizing the modified direct ELISA.

In the evaluation of the modified ToBi test, the high correlation coefficient of $96.76 \%$ obtained in the standard curve through simple linear regression guarantees the correlation among the values of absorbance and the epsilon toxoid titration, showing the efficiency of the curve in the evaluation of epsilon toxoid. The high correlation coefficient in a standard curve makes it safer to conclude that the increase of the absorbance values corresponds to a higher concentration of epsilon toxoid. The repetitions of analysis for the elaboration of the curve were similar among themselves, with a standard deviation not reaching $1 \%$. This fact shows the homogeneity of the results, thereby suggesting that a previously created standard curve may be used in the titration of serum tested in different plates, making the application of the method viable. However, it does not eliminate the need for negative controls in all negative and positive assays so as to guarantee the quality of the reagents and efficiency of the operator.

The results presented in Table 2 were as expected, since the toxoid concentration was directly proportional to the values of absorbance. In the results we can see that the ToBi test was more sensitive than the TCP methodology in vivo, since the values of toxoid titration obtained by the ToBi test were almost 500 times higher than results obtained by titration in vivo. This sensitiveness diminishes as the toxicoid concentration diminished; in the toxoid from batch $378 / 07$, the results obtained in vitro and in vivo were very similar. When the concentration of toxicoid is very high, the values of absorbance are very close to the maximum limit, the reading line being at $492 \mathrm{~nm}$ in the spectrophotometer, which goes from 0 to 2 , and the possibility of error is increased. Thus, the recommendation is to dilute the toxoid sample so the value of absorbance is close to 1 . In this study, the experiment was conducted by diluting the in vivo, $2560 \mathrm{TCP} / \mathrm{mL}$ toxoid in 1:4 dilution. Values of absorbance between 0.800 and 0.900 were obtained, corresponding to the TCP values from 432 to 848 , values close to the values obtained in vivo.

The results obtained demonstrated that the test may be utilized in triage methods, for it is sensitive and capable of detecting epsilon toxicoid and differentiating the quality of each one. Therefore, the results call for improvements and can be used as an option in bioassays in the future, contributing thus to the reduction in the number of animals utilized. However, the ToBi test modified for the analysis of epsilon toxoid needs to be tested with a greater number of samples so its performance is evaluated and it is considered safe to be made available to manufacturers of clostridial vaccines.

In literature there are few studies which utilize the ToBi test with the objective of evaluating 
toxicoid for the production of veterinary vaccines.

\section{CONCLUSION}

This work concluded that the modified direct ELISA test showed no promising results. It was not capable of discriminating different quantities of toxoids in the sample, thus making it unviable for this purpose. Regarding the ToBi test, it may be utilized in methods of antigen quality control. These results showed that it is an option for bioassays in the future, contributing thus to the reduction in the number of animals utilized. However, the ToBi test modified for the analysis of epsilon toxoid needs to be tested with a greater number of samples so its performance is evaluated and it is considered safe to be made available to manufacturers of clostridial vaccines.

\section{ACKNOWLEDGEMENTS}

We acknowledge Vallée S/A for supporting this work.

\section{REFERENCES}

BRANDI, I.V. Avaliação das condições de crescimento de Clostridium perfringens tipo $B e$ da produção de toxinas utilizadas na produção de vacinas veterinárias. 2000. 45f. Dissertação (Mestrado em Ciência e Tecnologia de Alimentos) - Universidade Federal de Viçosa, Viçosa, 2000.

BRANDI, I.V. Desenvolvimento e análises de validação de metodologias para o controle de processo de purificação e fabricação de vacinas contra Clostridium perfringens tipo D. 2007. 160f. Tese. (Doutorado em Biotecnologia) Programa de Pós-Graduação Interunidades em Biotecnologia USP/ Instituto Butantan/IPT, Universidade de São Paulo, São Paulo, 2007.

EL IDRISSI, A.H.; WARD, G.E. Development of double sandwich ELISA for Clostridium perfringens beta and epsilon toxins. Vet. Microbiol., v.3, p.89-99, 1992a.

EL IDRISSI, A.H.; WARD, G.E. Evaluation of enzyme-linked immunosorbent assay for diagnosis of Clostridium perfringens enterotoxemias. Vet. Microbiol., v.31, p.389-396, 1992b.
FAYEZ, M.M.; EL-MENISY, A.A.; HUSSEIN, A.Z. In vitro estimation of potency of some clostridial toxoid. Assiut Vet. Med. J., v.51, p.368-373, 2005.

HATHEWAY, C.L. Toxigenic Clostridia. Clin. Microbiol. Rev., v.3, p.66-98, 1990.

NAGAHAMA, M.; KOBAYASHI, K.; OCHI, S.; SAKURAI, J. Enzyme-linked immunosorbent assay for rapid detection of toxins from Clostridium perfringens. FEMS Microbiol. Lett., v.68, p.41-44, 1991.

REED, L.J.; MUENCH, H. A simple method of estimating fifty per cent endpoints. Am. J. Hyg., v.27, p.493-497, 1938.

SOBRINHO, E.M.; ALMEIDA, A.C; SANTOS, H.O. et al. Modified toxin-binding inhibition (ToBI) test for quantification of epsilon antitoxin in serum from immunized sheep. Acta Vet. Bras., v.5, p.326-330, 2011.

SOBRINHO, E.M.; ALMEIDA, A.C.; SANTOS, H.O. et al. Evaluation of the flocculation limit tecnhnique for quality control of clostridial vaccines. Acta Vet. Bras., v.3, p.151-156, 2009.

SOBRINHO, E.M.; CANGUSSU, A.S.R.; BRANDI, I.V. et al. Modified toxin-binding inhibition (ToBI) test for epsilon antitoxin determination in serum of immunized rabbits. Vet. Immunol. Immunop., v.138, p.129-133, 2010.

UNITED STATES. United States Department of Agriculture. In: CODE of Federal Regulations. Washington: United States Department of Agriculture. Part 113, p.618-748, 2006.

UZAL, F.A.; KELLY, W.R.; THOMAS, R. et al. Comparison of four techniques for the detection of Clostridium perfringens type D epsilon toxin in intestinal contents and other body fluids of sheep and goats. J. Vet. Diagn. Invest., v.15, p.94-99, 2003.

UZAL, F.A.; NIELSEN, K.; KELLY, W.R. Detection of Clostridium perfringens type D epsilon antitoxin in serum of goats by competitive and indirect ELISA. Vet. Microbiol., v.51, p.223-231, 1997.

WALKER, P.D.; FOSTER, W.H.; KNIGHT, P. A. et al. Development, preparation and safety testing of a Clostridium welchii type C toxoid. I: preliminary observations in man in Papua New Guinea. J. Biol., v.7, p.315-323, 1979. 